\title{
Treibt Toxoplasma Frauen in den Suizid?
}

\section{Der im Katzenkot vorkommende Parasit Toxoplasma gondii steht schon lange im Verdacht, Schizophrenie und andere Verhaltensstörungen zu ver- ursachen. Eine Studie mit den Daten von 45788 Däninnen erkennt jetzt einen Zusammenhang zwischen Toxo- plasmose und Suizid.}

- Frauen mit Toxoplasmose haben ein deutlich höheres Risiko Suizid zu begehen. Nach einer Studie der Universität Aarhus war die Inzidenz von Suizidversuchen bei Frauen, die eine Toxoplasmose durchgemacht hatten, doppelt so hoch wie bei den nicht infizierten Kontrollen (RR 2,05; $95 \% \mathrm{CI}=0,78-5,20)$. Auffällig war auch der Anstieg von Suizidversuchen mit hohem Gewalteinsatz (RR 1,54; 95\% CI = 0,98-2,39).

Toxaplasmen gelangen durch nicht ausreichend gegartes Tierfleisch und/ oder durch Katzenkot in den menschlichen Körper. Katzenkot kann selbst in Staubform und noch nach Jahren krankheitserregend wirken. Die Krankheit bleibt in der Regel latent, kann aber auch Lungenentzündung und Hautausschläge auslösen.

Besonders gefährlich ist die Infektion für schwangere Frauen: Der Ausbruch der Krankheit kann zu Fehlgeburten

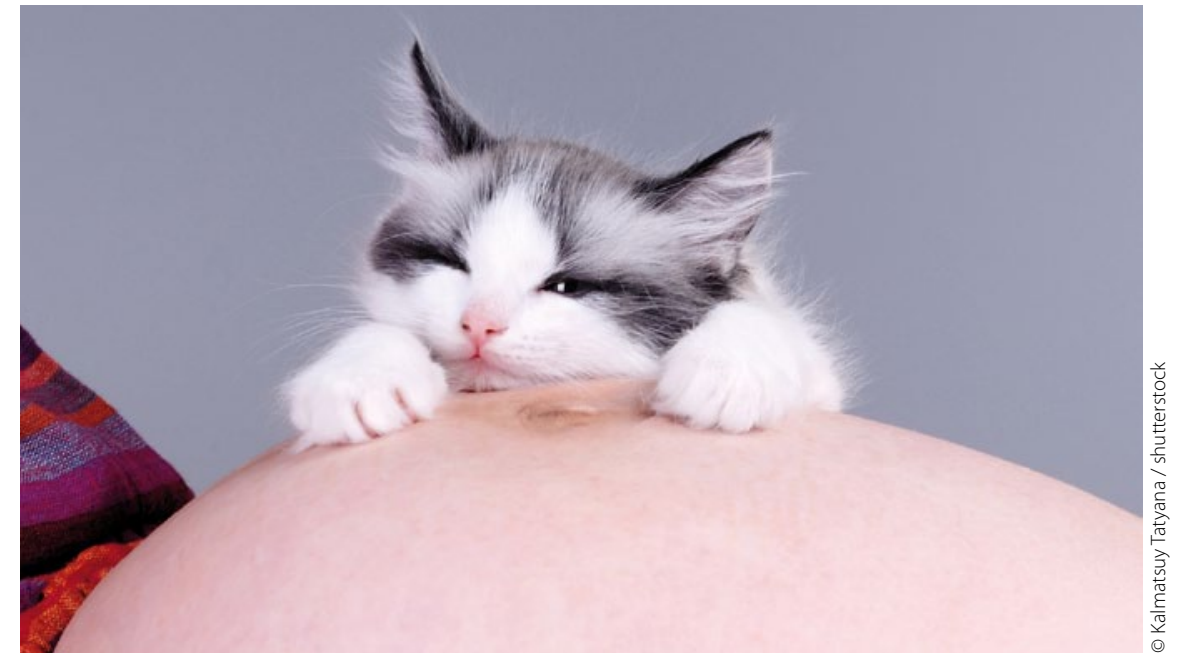

Katzenkot kann selbst nach Jahren noch Toxoplasmose auslösen.

führen oder Missbildungen sowie schwere Erkrankungen des Neugeborenen verursachen.

\section{Kommentar}

Es kann nicht mit Sicherheit gesagt werden, dass Toxoplasma gondii die Suizidversuche der Frauen verursachte. Aber offensichtlich besteht eine Verbindung zwischen der Infektion und den späteren Selbstmordversuchen. Vertiefende Studien sind bereits geplant. Rund ein Drittel aller Menschen infiziert sich im Laufe des Lebens mit den Toxoplasmose-
Erregern. Der nun vorgestellten Studie zufolge wächst das Suizidrisiko mit dem Level an Antikörpern.

K. MALBERG $=$

\begin{abstract}
- M. G. Pedersen et al.
(Department of Economics and Business, National Centre for Register-Based Research, Aarhus University, Taasingegade 1, 8000 Aarhus C, Denmark ; E-mail: mgp@ncrr.dk).. Toxoplasma gondii infection and self-directed violence in mothers. Published online on 02 July 2012 doi: 10.1001/archgenpsychiatry.2012.668
\end{abstract}

\section{USA erlauben HIV-Selbsttest}

In den USA wurde der erste freiverkäufliche HIV-Selbsttest zugelassen. Er benötigt keine Blutprobe und liefert in weniger als einer Stunde ein Ergebnis.

- Als enormen Fortschritt in der Erkennung des HI-Virus feierten die Arzneimittelaufsichtsbehörde FDA und der Gerätehersteller Ora-Sure-Technologies den HIV-Selbsttest, der jetzt die Zulassung in den USA erhalten hat. Das „Ora Quick In-home“ genannte Analysegerät soll im Oktober auf den Markt kommen und voraussichtlich weniger als 20 Euro kosten.

Für den Test wird ein Abstrich der Mundschleimhaut gebraucht. Das Ergebnis kann binnen 20 bis 40 Minuten abgelesen werden. Klinische Studien haben gezeigt, dass der Test $92 \%$ aller HIV-Erkrankungen erkennt. „Das heißt, falsch negative Ergebnisse bei HIV-Erkrankten sind immerhin bei jedem zwölften Test zu erwarten“, teilte die FDA mit.

\section{Kommentar}

Der Heimtest könne also keine letzte Sicherheit liefern, warnte die Behörde. Ein Arztbesuch bleibe erforderlich - vor allem dann, „wenn der letzte Kontakt (zu HIV-Infizierten) innerhalb der vorangegangenen drei Monate stattfand". Die Rate der falsch positiven Testergebnisse soll bei 1:5000 liegen.

\section{K. MALBeRG =}

- N. P. Pai et al.

The Lancet Infectious Diseases 2012 DOI: 10.1016/S1473-3099(11)70368-1 